\title{
Measles outbreak at an international airport: a Hong Kong perspective
}

\author{
$\mathrm{KL} \mathrm{Hon}^{1,2}$ *, MD, FAAP, Alexander KC Leung ${ }^{3}$, FRCP(UK), FRCPCH, Karen Leung ${ }^{1}$, MRCPCH, \\ Godfrey CF Chan ${ }^{1,4}$, MD, FRCPCH \\ ${ }^{1}$ Department of Paediatrics and Adolescent Medicine, The Hong Kong Children's Hospital, Kowloon Bay, Hong Kong \\ ${ }^{2}$ Department of Paediatrics, The Chinese University of Hong Kong, Shatin, Hong Kong \\ ${ }^{3}$ Department of Pediatrics, The University of Calgary and The Alberta Children's Hospital, Calgary, Alberta, Canada \\ ${ }^{4}$ Department of Paediatrics and Adolescent Medicine, The University of Hong Kong, Pokfulam, Hong Kong \\ *Corresponding author: ehon@hotmail.com
}

Hong Kong Med J 2019;25:331-3

https://doi.org/10.12809/hkmj197962

Measles (rubeola) is a highly contagious childhood vaccine-preventable disease caused by the measles virus. ${ }^{1,2}$ Complications occur in $10 \%$ to $40 \%$ of affected patients, and treatment is mainly symptomatic., ${ }^{1,-6}$ In developed countries, routine immunisation with measles-containing vaccine is recommended with the first dose at age 12 to 15 months and the second dose at age 4 to 6 years. ${ }^{7,8}$ In regions with high rates of measles transmission, the World Health Organization (WHO) recommends that the first dose of measles-containing vaccine be given at age 9 months and the second dose at age 15 to 18 months. ${ }^{9}$ Studies have shown that one dose of measles vaccine given at or after 1 year of age is 93\% to $95 \%$ effective in protecting against measles whereas two doses given at appropriate intervals is close to $100 \%$ effective. ${ }^{8}$ Measles vaccination given to susceptible contacts within 72 hours of exposure is effective in preventing illness or modifying the severity of the illness. ${ }^{9,10}$

Recently, outbreaks of measles have been reported globally, especially in Asia. ${ }^{1,11,12}$ An outbreak in early 2019 at the Hong Kong International Airport also created a public health concern, with wide national media coverage. ${ }^{13}$ Between March and mid-May 2019, 73 individuals were identified to have been infected with measles, including 29 airport workers. ${ }^{14}$

In general, patients with measles after vaccine failure were less ill than unvaccinated patients. Nevertheless, these patients required the same amount of effort from public health workers in tracing contacts. ${ }^{15}$ Of the 50 individuals infected with measles, six had two doses of measles vaccination.

It is expected that the immune system of a small percentage of individuals would not respond to the vaccine, resulting in primary vaccine failure. ${ }^{15}$ For those who were vaccinated but do not have sufficient antibodies, receiving a third dose might help boost their immunity; however, there is little scientific evidence to show how effective this third dose might be. ${ }^{15}$ Those who are worried might consider taking a blood test for measles antibodies to decide whether another dose of measles vaccine is necessary. Several issues have arisen with this airport outbreak.

\section{Issue 1: Protecting airport staff}

It is likely that airport staff contract measles by exposure to infected arriving tourists or aircrew. ${ }^{16,17}$ Individuals working at the airport typically had mild disease and did not spread the disease to their co-workers or family members, indicating that they are likely partly protected owing to prior vaccination. ${ }^{16}$ Infectivity is likely low, and these individuals need only be quarantined. Re-vaccinate their family members and close contacts may be unnecessary. It might be difficult, if not impossible, to identify visiting tourists with measles if they are asymptomatic. It might be unethical to quarantine asymptomatic arrivals even if they are from epidemic cities, and it would be impractical to demand these visitors provide evidence of measles vaccination. Aircrew members under age 52 years should be the first priority to receive booster measles vaccinations. Measles-containing vaccine should be given to those individuals who cannot readily provide evidence of immunity to measles as post-exposure prophylaxis. Aircrew who are exposed to a known case of measles but have no antibodies to measles should not be allowed to work, even after receiving post-exposure prophylaxis with measles vaccine. The Centers for Disease Control and Prevention recommends that medical staff who have no antibodies to measles should not be allowed to work for 5 to 14 days after exposure to measles, even after receiving postexposure prophylaxis with measles vaccine. ${ }^{18}$

\section{Issue 2: Prioritising vaccination}

In Hong Kong, most people born between 1967 and 1978 and many born between 1979 and 1984 received only one dose of measles vaccination. Those born before 1967 and after 1985 are supposed to be protected, although full immunisation does not 
guarantee full protection. ${ }^{16}$ In the event of inadequate immediate supply of vaccine for revaccination, it is reasonable to prioritise measles immunisation to the at-risk group, namely, those born between 1967 and 1978 and those working at the airport or in hospitals Drivers of public transport, taxis, and other transport become the next category of individuals for consideration of vaccination if the supply of vaccines remains inadequate. Other priority groups include those who were born in high-risk regions, such as the Philippines, Malaysia, and other places with inadequate vaccination policies, and those who have not received two doses of measles vaccinations and have not been infected with measles before.

\section{Issue 3: Blood testing}

Blood tests for measles antibodies take approximately 1 week before the results are available to determine the need to vaccinate. ${ }^{1}$ Initially, there were insufficient stocks of measles vaccines to administer to all vulnerable airport staff. The Department of Health provided the measles serology test service to airport staff and a cumulative total of 777 blood samples were collected. ${ }^{14}$

\section{Issue 4: Severe paediatric complications}

The risks of severe measles complications are very low. Paediatric complications such as encephalitis occur once in a million cases. ${ }^{1,6,19}$ However, amid the rise in measles infections, the Hong Kong Department of Health announced a change to existing measles vaccine policy so that children get their second dose of measles vaccine at an earlier age. $^{20}$ It is now recommended that children will receive the second dose of measles vaccine at age 18 months instead of at age 6 years.

\section{Issue 5: Infection control}

Several infectious diseases have been a cause for concern at Hong Kong International Airport, including SARS (severe acute respiratory syndrome), ${ }^{21}$ MERS (Middle East respiratory syndrome), ${ }^{22}$ Avian Influenza, and seasonal influenza. $^{23}$ Ordinary surgical masks are not designed for airborne infection and it is uncertain if aircrew and other staff wearing such masks plays any role in the prevention of spread of measles and other airborne diseases. ${ }^{24}$ For infectious diseases including measles, although infection control is an important gesture, universal immunisation is the definitive management strategy. ${ }^{1,3,6,8,9}$ The rise of anti-vaccination material on social media has been connected to the dramatic increase in cases of measles and various vaccine-preventable communicable diseases. ${ }^{25}$ Healthcare workers should join efforts to promote immunisation as an effective healthcare policy in infection control. ${ }^{26}$

\section{Summary}

Epidemics of infectious diseases raise many dilemmas, such as the effectiveness of vaccination programmes, which groups are most at risk, and how to prioritise further treatment or vaccination. In Hong Kong, the measles outbreak at the airport has resulted in an inadequate supply and stock of measles vaccines to meet local demand; sufficient vaccine supply should be secured as soon as possible. It is recommended to vaccinate first those aircrew who routinely fly to outbreak regions, followed by all other airport staff, including the shop assistants and janitors. Taxi drivers and drivers of public transport, and staff at local hotels may be included in the second wave. Fortunately, there have been no serious cases so far.

\section{Author contributions}

All authors contributed to the concept of study, acquisition and analysis of data, drafting of the article, and critical revision for important intellectual content. All authors had full access to the data, contributed to the study, approved the final version for publication, and take responsibility for its accuracy and integrity.

\section{Conflicts of interest}

As an editor of the journal, KL Hon was not involved in the peer review process. Other authors have no conflicts of interest to disclose.

\section{Funding/support}

This research received no specific grant from any funding agency in the public, commercial, or not-for-profit sectors.

\section{References}

1. Leung AK, Hon KL, Leong KF, Sergi CM. Measles: a disease often forgotten but not gone. Hong Kong Med J 2018;24:512-20.

2. Moss WJ. Measles. Lancet 2017;390:2490-502.

3. Caldararo S. Measles. Pediatr Rev 2007;28:352-4.

4. Rota PA, Moss WJ, Takeda M, de Swart RL, Thompson KM, Goodson JL. Measles. Nat Rev Dis Primers 2016;2:16049.

5. Nelson E, Tam JS, Yu LM, Glass RI, Parashar UD, Fok TF. Surveillance of childhood diarrhoeal disease in Hong Kong, using standardized hospital discharge data. Epidemiol Infect 2004;132:619-26.

6. MacFadden DR, Gold WL. Measles. CMAJ 2014;186:450.

7. Strebel PM, Cochi SL, Hoekstra E, et al. A world without measles. J Infect Dis 2011;204 Suppl 1:S1-3.

8. Bester JC. Measles and measles vaccination: a review. JAMA Pediatr 2016;170:1209-15.

9. World Health Organization. Measles Vaccines: WHO Position Paper, April 2017-Recommendations. Vaccine 2019;37:219-22.

10. Kumar D, Sabella C. Measles: back again. Cleve Clin J Med 2016;83:340-4.

11. Kobaidze K, Wallace G. Forgotten but not gone: update on measles infection for hospitalists. J Hosp Med 2017;12:472- 
6.

12. Shimizu K, Kinoshita R, Yoshii K, et al. An investigation of a measles outbreak in Japan and China, Taiwan, China, March-May 2018. Western Pac Surveill Response J 2018;9:25-31.

13. Centre for Health Protection, Hong Kong SAR Government. Daily update on measles situation in Hong Kong. Available from: https://www.chp.gov.hk/files/pdf/daily_update_on measles_cases_in_2019_eng.pdf. Accessed 13 May 2019.

14. Hong Kong SAR Government. Press release. Outbreak of measles infection at airport concluded. 2019 May 17. Available from: https://www.info.gov.hk/gia/general/ 201905/17/P2019051700868.htm. Accessed 13 May 2019.

15. Cherry JD, Zahn M. Clinical characteristics of measles in previously vaccinated and unvaccinated patients in California. Clin Infect Dis 2018;67:1315-9.

16. Chen CJ, Lin TY, Huang YC. Letter to the editor: Occurrence of modified measles during outbreak in Taiwan in 2018. Euro Surveill 2018;23(37):pii1800485.

17. Kondo Y, Tanimoto T, Kosugi K, et al. Measles vaccination for international airport workers. Clin Infect Dis 2017;64:528.

18. McLean HQ, Fiebelkorn AP, Temte JL, Wallace GS; Centers for Disease Control and Prevention. Prevention of measles, rubella, congenital rubella syndrome, and mumps, 2013: summary recommendations of the Advisory Committee on Immunization Practices (ACIP). MMWR Recomm Rep 2013;62:1-34

19. Fisher DL, Defres S, Solomon T. Measles-induced encephalitis. QJM 2015;108:177-82.

20. Cheung T, Lum A. Hong Kong set to change measles vaccine policy so children get second injection at earlier age amid rise in infections. 2019 Mar 27. Available from: https:// www.scmp.com/news/hong-kong/health-environment/ article/3003500/hong-kong-change-measles-vaccinepolicy-so. Accessed 13 May 2019.

21. Hon KL. Severe respiratory syndromes: travel history matters. Travel Med Infect Dis 2013;11:285-7.

22. Hon KL. MERS=SARS? Hong Kong Med J 2015;21:478.

23. Wong AT, Chen H, Liu SH, et al. From SARS to avian influenza preparedness in Hong Kong. Clin Infect Dis 2017;64(suppl_2):S98-S104.

24. MacIntyre CR, Chughtai AA, Rahman B, et al. The efficacy of medical masks and respirators against respiratory infection in healthcare workers. Influenza Other Respi Viruses 2017;11:511-7.

25. Taylor LE, Swerdfeger AL, Eslick GD. Vaccines are not associated with autism: an evidence-based meta-analysis of case-control and cohort studies. Vaccine 2014;32:3623-9.

26. Maglione MA, Gidengil C, Das L, et al. Safety of vaccines used for routine immunization in the United States. Evid Rep Technol Assess (Full Rep) 2014;(215):1-740. 